\title{
TEATRO-NAÇÃO: O ÉPICO NA DRAMATURGIA DE AUGUSTO SOBRAL
}

Agnaldo Rodrigues da Silva ${ }^{1}$

O teatro em cada país não deve ser um divertimento público, mas uma instituição nacional (Artur Azevedo).

\begin{abstract}
Resumo: O texto Os Degraus, do português Augusto Sobral, foi publicado em 1964, momento de intensa opressão do sistema de governo vigente em Portugal. Notadamente contestadora, essa exemplaridade da moderna dramaturgia portuguesa instaura uma nova forma de produção teatral, por meio da revitalização de mitos para discutir o presente. Nessa direção, o texto discute o mito de Prometeu (personagem que representa os anseios dos portugueses) em espaço e tempo moderno, meio a estagnação cultural da sociedade portuguesa da década de 1960. Levam-se aos palcos, desse modo, o confronto entre o Capitalismo e o Socialismo, criando o espaço necessário para a discussão de concepções ideológicas. De outro modo, a peça $O s$ Degraus incluiu Sobral no cânone da literatura de língua portuguesa, como texto cênico, cuja estética revigora elementos fundamentais do gênero, como, por exemplo, a cenografia.
\end{abstract}

Abstract: Os Degraus, by Sobral, it was published in 1964, a time of intense oppression of the government system in force in Portugal. Notably rebellious, this exemplary drama of modern Portuguese introduces a new form of theatrical production, through the revitalization of myths to discuss this. In this sense, the text discusses the myth of Prometheus (character who represents the aspirations of the Portuguese) in space and time modern cultural stagnation through the Portuguese society of the 1960s. They take to the stage, so the clash between capitalism and socialism, creating the necessary space for the discussion of ideological conceptions. Otherwise, the play The Sobral Steps included in the canon of literature in Portuguese, such as text scenic, aesthetic which reinvigorates the fundamental elements of the genre, for example, the set design.

Palavras-chave: Teatro, sociedade, política.

Keywords: Theatre, society, politics.

\section{CONCEITOS EM CONFRONTO COM A FICÇÃO}

O teatro épico é um gênero que demonstra um grande avanço em relação à dramaturgia clássica, aristotélica, pois sua prática está baseada na tensão dramática, no conflito e na progressão regular da ação. Rebello (2000), compilador de informações relevantes sobre o teatro português, afirma que o teatro épico, junto ao do absurdo,

1 Docente do Programa de Mestrado em Estudos Literários - PPGEL, da Universidade do Estado de Mato Grosso. Coordenador do Centro de Pesquisa em Literatura da UNEMAT e Coordenador do Grupo de Pesquisa em Estudos da Arte e da Literatura Comparada CNPq. 
formou uma forte matriz que se somou aos esforços para o derrube do regime vigente na nação portuguesa, na década de 1960 do século XX. Nessa direção, pode-se afirmar que

o retrato da situação do teatro no período que precede imediatamente a Revolução de 1974 contém-se em dois documentos datados do ano anterior, cuja divulgação a censura travou: uma comunicação apresentada ao II Congresso Republicano de Aveiro e uma exposição da Sociedade de Autores. Naquele denunciava a hipocrisia de uma legislação em que "princípios gerais aparentemente saudáveis (eram) na realidade cerceados ou completamente anulados no plano real através de proibições e, sobretudo, de uma estranguladora e asfixiante centralização". No segundo, procedia-se ao (longo) inventário de textos originais proibidos pela censura e protestava-se contra a diminuição crescente dos que haviam sido autorizados a subir à cena nas temporadas mais recentes: quatro em 1971, um em 1972, nenhum em 1973...". E, no entanto, escreveram-se e publicaram-se entre 1945 e 1974 mais peças em Portugal do que em muitas outras épocas.

De matriz brechteana, a tendência teatral desse período instituiu uma dramaturgia de cariz sociopolítica empenhada na transformação das estruturas sociais, por meio de denúncias de situações injustas e da sua dialética superação, e, como tal, situada na órbita do neo-realismo literário. Nesse contexto, levaram-se aos palcos do teatro português textos de extrema aspereza perante as contradições da burguesia capitalista e, sobretudo, formou-se um foco de resistência contra a censura que havia sido forjada por um sistema de governo ditatorial. Foi por isso que, sobretudo, Brecht denominou o seu teatro épico de "peças de experimentos, na acepção das ciências naturais, com a diferença de se tratar de experimentos sociológicos". ii

Por esse motivo, entre outros, atribuiu-se a Augusto Sobral peças de rico substrato humano, entre as quais está Os degraus, uma notável leitura moderna do mito de Prometeu. Com identificáveis influências de Ionesco e Tchekov, o texto está datado de 1964, mas que a censura não deixou levar a cena pelo seu conteúdo fortemente político. Muitos anos mais tarde é que esta peça foi, finalmente, representada. Pelo distanciamento histórico, o presente se fazia reluzente na peça, dizendo o que de outro modo não poderia ser dito, como se a propor uma revisão crítica não só da história portuguesa, mas também da própria representação teatral, aspecto típico do teatro épico. Nessa direção, Rodrigues (2003) salienta que: 
Brecht, que buscava um teatro que dissociasse o público da prisão ideológica cotidiana da experiência, volta-se para o épico, com sua atmosfera de uma iluminação uniforme. Seu objetivo é tornar estranhos os acontecimentos e indivíduos, deslocando-se de suas relações familiares entre si e com o tema e, desse modo, propondo à atenção do público à possibilidade de uma relação diferente entre o universal e o particular. Com isso, procura apresentar a possibilidade de liberdade, começando por dar a seu público a oportunidade de pensar e sentir de maneira diferente. iii $^{\text {ii }}$

O texto, portanto, não foge ao tema fulcral que Sobral trabalha exaustivamente nas suas peças, ou seja, a solidão humana em um contexto sociopolítico conturbado. Tomando como motivo um mito antigo, discute-se a necessidade de libertação das consciências. Entram em ebulição a filosofia, a ciência, a religião e suas respectivas relações com todos os outros campos da experiência humana.

Tais questões fazem lembrar a proporção que o mito de Prometeu tomou a partir do Romantismo, principalmente na cultura ocidental. Passou a vigorar como o símbolo, por excelência, da revolta na ordem metafísica e religiosa, como que encarnasse a recusa do absurdo da condição humana, associado ao mito do fogo como prenúncio de uma nova era. Sobre esse mito, Silva (2008) afirma que

O mito de Prometeu está intimamente ligado ao mito da criação do mundo, no que se refere à mitologia grega. [...] Pensar o mito na modernidade pressupõe a quebra de conceitos pré-estabelecidos no tocante, principalmente, à ampliação do próprio conceito que se tem a respeito. De certo modo, a forma moderna de conceber o mito retira a moldura na qual este ficou limitado por muito tempo, uma limitação cujas referências eram a Grécia antiga ou Roma. No entanto, o tempo encarregou de modificar essas concepções, pois até mesmo a ideia de que os mitos deviam ser pagãos caiu por terra, colaborando para a formação de um eixo comum as duas ideias que eram vistas como antagônicas e inconciliáveis: mito pagão e mito cristão (logo, paganismo e cristianismo cruzam-se nessa mesma esfera). ${ }^{\text {iv }}$

Quando Sobral constrói o protagonista de Os Degraus, que leva a alcunha de Prometeu, aplicou-lhe as metamorfoses que o mito sofreu ao longo de todos esses séculos, até que se chegasse a uma personagem que fosse o emblema da luta contra a tirania e o poder constituído, na modernidade. As relações construídas no texto de Sobral forçam o aparecimento do homem, mas não qualquer homem, trata-se do homem-herói, o homem-deus. 
Os fenômenos históricos passam a circundar esses homens transformadores, cuja genialidade é menosprezada, incompreendida e, às vezes, perseguida pelos detentores do poder. Há um determinado momento da peça de Sobral que a personagem Prólogo refere-se ao Prometeu como aquele que está a fazer homens, sejam eles desesperados ou felizes, mas que, mesmo assim, faz homens porque os esclarece. É por isso que, certamente,

O personagem é marcado por uma espécie de "máscara" esquemática (comportamento, indumentária, adereços especiais) que, em vez de encobrir os diversos atores como ocorria na Grécia, deve "transparecer" através da variedade dos comediantes que já não "encarnam" o papel, mas são portadores e "narradores" dele. O caráter tenderá a ter, por isso, traços típicos, tornando-se, mais que indivíduos, representante de um grupo.

Rosenfeld (2002), portanto, ao discutir as características do teatro épico, afirma que o gênero épico é mais objetivo que o lírico, pois o mundo objetivo (naturalmente imaginário, na ficção) com suas paisagens, cidades e personagens (envolvidas em certas situações), exprime e expõe os estados de alma de outros seres, de uma coletividade. Imagina-se, portanto, no teatro épico, a presença de ouvintes ou interlocutores, a quem se descreveria objetivamente fatos sobre circunstâncias objetivas.

Nessa direção, Costa (1998) salienta que os artistas que se envolveram com o teatro épico tiveram toda sorte de inimigos a enfrentar, começando por aqueles que se faziam passar por aliados. A perseguição por parte da polícia política efetivamente forçou um teatro épico que se mantivesse, em muitos casos, apenas no papel, em um tipo de teatro feito para ser lido, não ultrapassando, por muito tempo, o estatuto do texto cênico. Esse caráter amplamente político do teatro português, desse período, revigora o fato de que

acompanhando uma tradição de historiadores do teatro moderno, entendemos que processos artísticos costumam responder a processos históricos. Para falar como um deles, formas artísticas são conteúdo histórico sedimentado e , quando uma obra explicita a necessidade de superação de alguma convenção vigente, ela está registrando, como um sismógrafo, abalos havidos na sociedade. ${ }^{\text {vi }}$

O Prometeu sobraliano é o típico homem solidário que, em determinados momentos, aproxima-se das características do herói ou do anti-herói. Isso não importa, porque o fim atingido é o emblema da luta coletiva. Consciência e inconsciência criam 
as janelas nas quais se desenvolvem as tramas, cujos heróis ou anti-heróis são, em potência, tudo que deveriam ser e não criações bitoladas dos sistemas sociais.

O ser humano é fruto da cidade em Os Degraus, e Prometeu é construído nesses moldes, isto é, o homem-cidade que dialoga com o espectador sobre as crises sociais, políticas, econômicas e existenciais, um prato cheio para fazer desta peça um inegável modo de escrever tragédias nos tempos modernos. A crise do homem moderno é posto nas mãos de um rapaz que nasceu em berço esplêndido, conhece a vida boa e o bom da vida, mas que protagoniza uma história que versa sobre a subsistência, como bem lembrou Midões: "não há nenhum código nem nenhum artigo que obrigue os dramaturgos a criarem sempre protagonistas-heróis-pombos-correios-de-mensagens". vii

O horizonte temático trabalhado em Os Degraus é bastante rico, tendo em vista que a visitação ao mito de Prometeu permite um trabalho humano e sociológico, no qual as coisas fluem não como simples apontamentos, mas como funcionalidade de fatos circundantes. Fadda (2001) faz afirmações que corroboram com este ponto de vista, pois para ela, esse posicionamento que Sobral tomou na produção da peça tem tudo a ver com o dever da participação dos artistas nas coletividades organizadas, da sua intervenção crítica perante as injustiças e aos vícios dos sistemas, posturas tornadas necessárias naquele momento histórico, cujo pano de fundo era o atraso de Portugal, "um Portugal pequenino, fruto da inércia forçada dos incultos e da repressão sobre os cultos. Um país que vive com os olhos voltados para as colônias, e que ainda sentia a necessidade de encaminhar seus filhos para morrerem nas terras da África”. viii

Há uma repulsa ao sistema constituído, àquela forma de estrutura das classes: opressores e oprimidos. A recusa em se integrar a esse sistema não leva a personagem a buscar alternativas que estejam pautadas na construção de valores interiores; porém, a empurra para uma luta interior que desemboca, justamente, numa auto-aniquilação.

A verdade torna-se abstrata, desligada dos atos, impedindo que o Prometeu de Sobral atinja a hierarquia dos heróis. Talvez tudo isso tenha sido um dos motivos pelo qual a crítica sempre frisou o que o autor propôs nessa peça: "uma visão amarga do mundo, a ineptidão do indivíduo para o transformar, colocando-se a margem e prescindindo da sua capacidade interveniente". ix 
Essa hostilidade que a elite teve em relação ao conteúdo de Os Degraus fez com que a encenação ficasse ausente, de modo que o Prometeu da tragédia moderna da literatura portuguesa acabasse "agrilhoado numa estante sem nenhum Héracles que o liberte até hoje". ${ }^{x}$ Lembremos de Boal (1975), ao discutir a poética de Brecht:

\begin{abstract}
A poética de Brecht é a Poética da Conscientização: o mundo se revela transformável e a transformação começa no teatro mesmo, pois o espectador já não delega poderes ao personagem para que pense em seu lugar, embora continue delegando-lhe poderes para que atue em seu lugar. A experiência é reveladora ao nível da consciência, mas não globalmente ao nível da ação. A ação dramática esclarece a ação real. O espetáculo é uma preparação para a ação. ${ }^{\text {xi }}$
\end{abstract}

Por esse viés focado por Boal, a poética do oprimido torna-se fundamentalmente um ato de libertação, em que o espectador assume o seu papel sociocultural, sem permitir que o outro atue por ele (no caso, a personagem). O espectador, portanto, gozando de liberdade de pensamento e ação, pensa e age por si mesmo $\mathrm{O}$ teatro passa a ser ação.

\title{
2 EM BUSCA DAS CONSIDERAÇÕES FINAIS
}

À guisa de uma conclusão, mesmo que temporária sobre esta investigação, façamos referência ao teatro-nação sob a perspectiva de Sá (2010). Sá, mesmo tendo realizado uma investigação no âmbito do teatro brasileiro, alguns de seus apontamentos norteiam a discussão sobre o teatro épico e o teatro-nação. Nesse contexto, o pesquisador afirma que:

As peças teatrais, como registro de um dos produtos vivos da expressão cultural do homem em sociedade, empreendem elementos importantes não só do tempo que representam, mas principalmente da maneira como o autor compreende seu tempo. Mesmo que os textos sejam limitados, enquanto textos cênicos, salienta-se que pelas possibilidades associativas e interpretativas estão permanentemente abertos. ${ }^{\text {ii }}$

Movidos pelas considerações acima e, ainda, pelo fato de que os conceitos de nação passam pelos filtros estabelecidos pela hierarquia da sociedade representada na peça focada neste texto, façamos referência a Anderson ${ }^{\text {xiii }}$ ao afirmar que a nação se configura como uma comunidade política imaginada - e imaginada como sendo inerentemente limitada e soberana. Do mesmo modo Hobsbawm ${ }^{\text {xiv }}$, que além de destacar o surgimento do Estado como determinante para a nação, afirma que a nação é 
qualquer corpo de pessoas suficientemente grande, cujos membros consideram-se como membros de uma nação. E certamente que as afirmações acima se somam na compreensão das verdadeiras intenções de um texto cênico épico.

Enfim, considera-se que a peça Os degraus, de Sobral, atinge patamares além de um status que a localiza como uma exemplaridade da tragédia moderna de língua portuguesa. Mas, sobremaneira, constitui um rico material para se discutir o teatronação, a partir dos elementos épicos identificáveis na estrutura do texto. O teatro-nação em que está configurada uma vontade coletiva de transformação sociopolítica, que somente a ficção seria capaz de articular nos bastidores da ditadura.

\section{REFERÊNCIAS BIBLIOGRÁFICAS:}

ANDERSON, Benedict. Nação e consciência nacional. In: SÁ, Jussara Bittencourt. Nação em cena. Florianópolis: UFSC, 2010.

BOAL, Augusto. Teatro do oprimido e outras poéticas políticas. Rio de Janeiro: Civilização Brasileira, 1975.

CAMARGO, Iná. Sinta o drama. Petrópolis, RJ: Vozes, 1998.

FADDA, Sebastiana. "O teatro e seus múltiplos". In: SOBRAL, Augusto. Teatro. Lisboa: Biblioteca de autores portugueses (Imprensa Nacional, Casa da Moeda), 2001.

HOBSBAWM, M.E. Nações e nacionalismos desde 1780. In: SÁ, Jussara Bittencourt. Nação em cena. Florianópolis: UFSC, 2010.

MIDÕES, Fernando. "Prefácio". In: SOBRAL, Augusto. Teatro. Lisboa: Presença, 1964.

REBELLO, Luiz Francisco. Breve história do teatro português. Portugal: Europa-América, 2000.

RODRIGUES, Agnaldo. O futurismo e o teatro. Tangará da Serra, A.R edições, 2003. 
ROSENFELD, Anatol. O mito e o herói no moderno teatro brasileiro. São Paulo: Perspectiva, 1982.

ROSENFELD, Anatol. O teatro épico. São Paulo: Perspectiva, 2002.

SÁ, Jussara Bittencourt. Nação em cena. Florianópolis: UFSC, 2010.

SILVA, Agnaldo Rodrigues. Projeção de mitos e construção histórica no teatro trágico. Campinas: Editora RG, 2008.

SOBRAL, Augusto. Teatro. Lisboa: Biblioteca de autores portugueses (Imprensa Nacional, Casa da Moeda), 2001.

SOBRAL, Augusto. Teatro. Lisboa: Presença, 1964.

\footnotetext{
${ }^{\mathrm{i}}$ REBELLO, 2000, p.147-148.

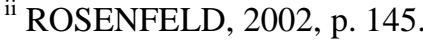

iii RODRIGUES, 2003, p. 92-93.

iv SILVA, 2008, p. 31.

${ }^{\mathrm{V}}$ ROSENFELD, 1998, p. 13.

${ }^{\text {vi }}$ COSTA, 1998, p. 183.

vii Apud SOBRAL, 1964, p. 20.

viii Apud Sobral, 2001, p. 17.

${ }^{\text {ix }}$ FADDA, apud Sobral, 2001, p. 20.

${ }^{x}$ Ibid., p. 20.

${ }^{x i}$ BOAL, 1975, p. 169.

${ }^{x i i}$ SÁ, 2010, p. 53.

xiii ANDERSON apud Sá, 2010, p. 30.

xiv Ibidem.
} 